\title{
Dış Ticaret Hadleri ve Ekonomik Büyüme İlişkisi: Türkiye Örneği
}

\section{Terms of Trade and Economic Development Relationship: The Case of Turkey}

\author{
Burçin ÇAKIR, Dokuz Eylül Üniversitesi, Türkiye, burcincakir_1990@hotmail.com \\ Orcid No: 0000-0002-8578-4929 \\ Utku UTKULU, Dokuz Eylül Üniversitesi, Turkey, utku.utkulu@deu.edu.tr \\ Orcid No: 0000-0002-8419-0598
}

\begin{abstract}
Öz: Bu çalışma, dlş ticaret hadlerinin ekonomik büyüme üzerindeki etkisini Türkiye örneğinde (1990-2015) incelemektedir. Çalışmada geleneksel birim kök testleri yanı sıra, tek kirllmalı ve çift karllmalı birim kök testleri uygulanmıştır. Dış ticaret hadlerinin büyüme üzerindeki kısa ve uzun dönem etkileri ARDL tahmin yöntemi kullanılarak analiz edilmiştir. Çalışmada GSYH bağımlı değişken olup, dış ticaret hadleri, reel döviz kuru ve dışa açıklı bağımsız değişkenler olarak ele alınmışıtır. Dış ticaret hadlerindeki pozitif bir etkinin reel geliri arttıracağın öneren Harberger-Laursen-Metzler etkisinin varllğı ampirik olarak doğrulanmıştır. Diğer bir deyişle, ekonometrik incelemeler sonucunda dış ticaret hadlerinin ekonomik büyüme üzerinde pozitif ve anlamlı bir etkisi olduğu bulgusuna ulaşılmıştır. ${ }^{l}$
\end{abstract}

Anahtar Kelimeler: Diş ticaret hadleri, Ekonomik Büyüme

Abstract: This study, examined the impact of terms of trade on economic growth in Turkey as a case study(1990-2015). In addition to the traditional unit root tests, single-breaking and double-breaks unit root tests were applied. The short and long term effects of terms of trade on growth were analyzed using ARDL estimation method. In this study, GDP is dependent variable and terms of trade, real exchange rate and openness are considered as independent variables.The existence of the Harberger-Laursen-Metzler effect, which proposes that a positive effect on terms of trade will increase real income, has been empirically confirmed. In other words, as a result of econometric studies, it was found that terms of trade had a positive and significant effect on economic growth.

Keywords: Terms of Trade, Economic Development

\section{Giriş}

Ülkeler, coğrafi farklılıklar, iklim, teknoloji, yetişmiş işgücü gibi üretim farklılıkları ve buna ek olarak fiyat farklılıkları, tüketici zevkleri gibi etkenlerden dolayı birbirleriyle ticari ilişkiler kurar. Bu ilişkiler ise ülkelerin refah kazancına ya da refah kaybına yol açabilir. Ülkelerin ticari ilişkiler sonucu refah kazancı ya da refah kaybını belirleyen araç ise dış ticaret hadleridir.

Geçmişten bugüne mübadele oranı, reel mübadele oranı, trampa ticaret hadleri olarak adlandırılsa da, diş ticaret hadleri (terms of trade) kavramı ilk kez Alfred Marshall tarafından kullanılmıştır. Dış ticaret hadleri kavramı genellikle ihracat fiyat endeksi ile ithalat fiyat endeksi arasında bir oran olarak nitelendirilmektedir. Bu bağlamda iki ülkenin ticari ilişkileri sonucunda ihracat fiyatları ithalat fiyatlarına göre oransal olarak fazla olan ülke gerçekleşen ticaret sonucu refah kazancı elde ederken, ithalat fiyatları artan ihracat fiyatları azalan ülke için refah kaybı elde etmesi anlamına gelmektedir. Dolayısıyla gerçekleşen dış ticari ilişkilerin kazanç $\mathrm{m}$ kayıp $\mathrm{m}$ getireceği büyük önem arz ederken bu hususta en önemli araç dış ticaret hadleridir. Bu ölçüm yapılırken ihracat ve ithalat endeksleri yardımıyla dış ticaret hadleri karşılaştırılarak yorum yapılır. Dış ticari ilişkilerde olumlu yönde seyir izleyen ülkede gelir farkı azalır, kişi başına düşen gelir artar. Bu durum ise ülkenin dış ticarette rekabet gücünü arttırır ve ülke refahının artmasını sağlar.

İktisadi büyüme, zaman içinde mal ve hizmet üretimi miktarında artış olmasıdır. Dış ticaret hadleri ekonomik büyüme üzerinde iki kanaldan etki yaratmaktadır. Bu kanallar arz ve talep etkisidir. Bireylerin gelir artışının bir sonucu olarak ithalat talebinde meydana gelen artış talep etkisi yoluyla büyümeyi ifade etmektedir. Örnek olarak, Türkiye' de dışa dönük ticaretin benimsenmesi ile birlikte ithalata dayalı bir büyüme söz konusudur. Mukayeseli Üstünlükler çerçevesinde daha ucuza mal edilen dış alım, gelişmekte olan ülkelerin ihracatını dolayısıyla ekonomik büyümesini arttırıcı bir unsurdur. Fakat giderek artan ihracat bir yandan ekonomik büyümeyi gerçekleştirirken, diğer bir taraftan ithalata bağımlı hale getirmektedir. Buna ek olarak, gelişmekte olan ülkeler, döviz geliri elde edemedikleri için, ödemeler dengesi açık vermekte, dış ticaret hadleri kötüleşmekte bu ise ekonomik büyümeyi olumsuz etkileyerek, ekonomik kırılganlığı arttırmaktadır. Dolayısıyla ithalata bağımlı büyüme sahte bir büyümedir(Gerni, Emsen ve Değer: 2008). Arz etkisi ile büyüme ise ülkelerin ihracat yapılarının nitelik olarak ne kadar güçlü olduğu ile ilişkilidir. Yeni teknolojileri benimseyen,

${ }^{1} \mathrm{Bu}$ makale aynı başlıkla BOR Konferansı' nda sunulmuş bildirinin revize edilmiş halidir. Ayrıca bu çalışmanın orijinal hali Dokuz Eylül Üniversitesi Sosyal Bilimler Enstitüsü'nde Prof. Dr. Utku Utkulu danışmanlığında başarıyla savunulmuştur.

Makale Gecmiși / Article History

Başvuru Tarihi / Date of Application : 7 Ekim / October 2019

Kabul Tarihi / Acceptance Date : 10 Kasım / November 2019 
nitelikli işgücü oluşturan, pazar payını genişleten ülkeler ihracatın ithalatı karşılama oranını yükselterek dış ticaret hadlerini ve dolayısıyla dış ticaret dengesini olumlu etkileyerek gayri safi yurt içi hasıladaki artış sağlanarak ekonomik büyümeyi hızlandıracaktır (Bal, Çiftçi, İşcan ve Serin: 2016).

Talep etkisi ve arz etkisi arasındaki ilişki dış ticaret hadlerinin ekonomik büyüme üzerindeki etkisini belirlemektedir. Talep etkisinin, arz etkisinden büyük olduğu durumda söz konusu ülkenin ticaret hadlerinde negatif etki yaratır. Öte yandan arz etkisi talep etkisinden daha baskın olması durumunda, ülkelerin ticaret hacmi artar. İhracattaki artış dış ticaret hadlerinde pozitif bir etkiye sebep olur ve bu etki ise ekonomik büyümeyi oluşturur.

Bu çalışmada OECD ve TÜİK verilerinden yararlanılarak 1990-2015 çeyreklik dönemde dış ticaret hadlerinin ekonomik büyüme üzerindeki etkisi Türkiye bağlamında incelenecektir. Dört bölümden oluşan çalışmanın ikinci bölümünde literatür taraması, üçüncü bölümde araştırma çerçevesinde uygulanan yöntem tanıtılmış olup, dördüncü bölümde ise veri seti ve ampirik analiz sonuçlarına yer verilmiştir. Beşinci olarak sonuç bölümünde ulaşılan bulgular çerçevesinde politika önerileri ortaya konulmuştur.

\section{Literatür Taraması}

Dış ticaret hadlerinin ekonomik büyüme üzerindeki etkileri ile ilgili bilgi sağlayan sayısız çalışma bulunmaktadır. Genellikle Literatürde dış ticaret hadleri ve ekonomik büyüme olguları arasındaki ilişkinin pozitif yönlü olduğu sonucuna ulaşılmıştır.

Mendoza(1997), yapmış olduğu Terms of Trade Uncertainty and Economic Growth adlı çalışmasında dış ticaret haddi ile ekonomik büyüme ilişkisini incelemiştir. Bu çalışmasında, 40 ülkeyi ele almıştır. Bu ülkelerden 9'u gelişmiş, diğer 31 ülke ise gelişmekte olan ülkelerdir. 1971-1991 yılları ele alınarak yapılan çalışmanın sonucunda, dış ticaret hadleri ile ekonomik büyüme arasındaki ilişki pozitif yönlü bulunmuştur.

Çakır (2009), yapmış olduğu çalışmasında 1990-2004 yıllarını ele almıştır. 18 gelişmekte olan ülkeyi ele alan çalışmasında panel veri yaklaşımı ve araç değişkenler ile birlikte dış ticaret hadleri ve ekonomik büyüme arasındaki ilişkiyi incelemiştir. Araştırmanın sonucuna göre dış ticaret hadleri ve ekonomik büyüme arasında pozitif ilişki olduğu sonucu ortaya çıkmaktadır.

Christopher Blattman, Jason Hwang, Jeffrey G. Williamson'ın The Terms of Trade and Economic Growth in the Periphery 1870-1938 yapmış olduğu çalışmasında, II.Dünya Savaşı öncesi verilerini ele almıştır. 1870-1938 yılları verileri ile 35 ülke analiz edilmiştir. Bu ülkelerden 19'u gelişmiş, 16's1 gelişmekte olan ülkelerdir. Analiz sonucuna göre, diş ticaret hadlerindeki değişkenlik gelişmiş ülkeleri az etkilerken, gelişmekte olan ülkeleri daha çok etkilemiştir. Gelişmekte olan ülkelerin bu değişkenliğin getirdiği zararın etkisini daha yoğun yaşadığı sonucuna ulaşmıştır.

Cashin ve Mcdermott, Terms of Trade Shocks and Current Account adlı çalışmasını 1988 yılında yayınlamıştır. Bu çalışmada Harberger-Laursen-Meltzer'in gelir etkisi görüşünün dış ticaret hadlerinde meydana gelen negatif geçici bir şokun, ele alınan ülkenin cari gelirini, sürekli gelirinden daha fazla oranda azaltacağını ifade etmiştir.

Sfreddo, International Price and Terms of Trade Effects on Factor Productivity adlı çalışmasını 2004 yılında yayınlamış ve çalışmasında dış ticaret hadlerinin sabit olduğu durumda bile, hem işgücü hem de sermaye sahiplerinin refah düzeyini etkileyeceğini açıklamıştır.

Jawaid ve Waheed (2011), 2004-2008 yılları ve 94 ülkeyi ele alan çalışmasında dış ticaret hadlerinin ve dış ticaret hadlerindeki değişimin (oynaklığın) ekonomik büyüme üzerindeki etkisi analiz etmiştir. Bulgular diş ticaret hadlerinin ve dış ticaret hadlerindeki değişimin büyümeyi pozitif yönde etkilediği yönündedir.

Jawaid, Raza (2013) Effects of Terms of Trade on Growth Performance of India adlı çalışmasında 1980-2010 yıllarını baz almıştır. Ele alınan verilerle koentegrasyon analizi yapılış ve çalışma sonucu dış ticaret hadleri ve ekonomik büyüme ilişkisi arasında uzun ve kısa dönemde pozitif ilişki olduğu sonucuna ulaşmıştır.

Ekinci, Tüzün ve Kahyaoğlu (2015) Markow Değişim Tekniği yaklaşımı yardımıyla yaptıkları çalışmalarında Türkiye'nin dış ticaret hadlerinde meydana gelen olumlu gelişmelerin büyümeyi pozitif olarak etkilediği sonucuna ulaşmışlardır.

Hadas ve Williamson (2003) yapmış oldukları çalışmada ele aldıkları ülkeleri gelişmiş ve gelişmekte olan ülkeler olarak sınıflandırmışlar ve bu ülkeleri 1870- 1940 yılları itibariyle ekonomik büyüme ve dış ticaret hadleri ilişkilerini incelemişlerdir.. Çalışmalarında gelişmiş ve gelişmekte olan ülkelerde ekonomik büyümenin etkilerinin asimetrik olduğunu belirten güçlü kanıtlar bulmuşlardır.

Misztal, (2010) Polonya için yapmış olduğu çalışmasında Harberger- Laursen- Metzler etkisini 1995- 2009 yılları içerisinde analiz etmiştir. Çalışma Vektör otoregresif yaklaşımına dayalıdır. Bu analiz sonucunda, Polonya' da dış ticaret hadlerinin ülkenin lehine gelişerek cari dengede iyileşme yarattığını, daha sonra ise bozulmaya neden olduğu anlaşılmıştır. Literatürde S eğrisi olarak da bilinen bu durum, Polonya ekonomisinin 1995-2009 yıllarını yansıtmaktadır.

Bu çalışma ise 1990-2015 çeyreklik verileri ele alınarak, ekonomik büyümeyi ifade eden GSYİH bağımlı değişkeni ile reel kur, dışa açıklık ve dış ticaret hadleri bağımsız değişkenleri ele alınarak Türkiye örneği üzerinden hareketle dış ticaret hadlerinin ekonomik büyüme üzerinde nasıl bir etki yaratacağı sorusuna cevap niteliğindedir. 


\section{Veri Seti, Yöntem ve Bulgular}

Çalışmada 1990-2015 çeyreklik verileri ele alınırken OECD ve TÜİK verilerinden yararlanılmıştır. Ekonomik büyümeyi ifade eden GSYİH bağımlı değişken olup, reel kur, dışa açıklık, dış ticaret hadleri bağımsız değişkenlerdir. Yöntem olarak geleneksel birim kök testlerinin yanı sıra tekli ve çoklu kırılmaları dikkate alan birim kök testleri uygulanmıştır. Buna ek olarak değişkenlerin entegrasyon derecelerindeki farklılıklar sebebiyle ARDL modeli uygulanacaktır. Çalışmanın bir diğer önemli özelliği ise Bai-Perron testi ile kırılma yılları ARDL modeline eklenerek değişkenlerin güvenilirliliğinin arttırılmasıdır. Bu noktada çalışma, literatüre katkı niteliği taşımaktadır.

Bu kısımda öncelikle analize konu olan değişkenlerin durağanlık düzeyleri test edilmektedir. ${ }^{2}$ Bunun için birim kök testlerinden yararlanılmaktadır Tablo 5' de ise birim kök testlerinin sonuçları yer almaktadır. Birim kök testi ile entegrasyon düzeyleri belirlendikten sonra değişkenler arasında uzun dönemli bir eştümleşme ilişkisinin olup olmadığg test edilmektedir. Burada çalışmanın amacı çerçevesinde oluşturulan modele ait kısa ve uzun dönem katsayılar tahmin edilmektedir. Elde edilen katsayı tahmincileri yorumlanarak çalışmanın sonuç kısmına geçilmektedir

Çalışmanın bu bölümünde ilk olarak geleneksel birim kök testleri ADF, Philips Perron, KPSS Test İstatistiği daha sonra tek kırılmayı dikkate alan Zivot-Andrews Birim Kök Testi ve çift kırılmalı birim kök testi Lumsdaine- Papell Birim Kök Testi, Lee-Strazicich Birim Kök Testi uygulanacaktır. ${ }^{3}$ Modelde değişkenlerin entegrasyon derecelerinin farklı olması Tablo 5'de ifade edilmiştir. Entegrasyon derecelerinin farklı olması sebebiyle ARDL eştümleşme testi uygulanacaktır.

Tablo 1. Geleneksel Birim Kök Testleri(ADF, PP, KPSS)

\begin{tabular}{|c|c|c|c|c|c|c|c|}
\hline & & \multicolumn{2}{|c|}{ ADF Test istatistiği } & \multicolumn{2}{|c|}{ PP Test istatistiği } & \multicolumn{2}{|c|}{ KPSS Test istatistiği } \\
\hline & & Düzey & Birinci Fark & Düzey & Birinci Fark & Düzey & Birinci Fark \\
\hline \multicolumn{2}{|c|}{$\ln G D P$} & $-0.939(1)$ & $-7.552(0)^{* * *}$ & $-0.681(10)$ & $-7.389(4)^{* * *}$ & $1.098(8)$ & $0.120(1)^{* * *}$ \\
\hline \multicolumn{2}{|c|}{$\operatorname{lnDTH}$} & $-5.021(1)^{* * *}$ & $-7.246(3)^{* * *}$ & $-3.036(12)^{* *}$ & $-7.716(4)^{* * *}$ & $0.153(4)^{* * * *}$ & $0.110(24)^{* * *}$ \\
\hline \multicolumn{2}{|c|}{$\ln R E R$} & $-1.793(0)$ & $-8.851(0)^{* * *}$ & $-1.671(21)$ & $-9.111(7)^{* * *}$ & $0.923(8)$ & $0.260(57)^{* * *}$ \\
\hline \multicolumn{2}{|c|}{$\ln O P$} & $-1.920(0)$ & $-9.874(0)^{* * *}$ & $-1.935(4)$ & $-9.875(2)^{* * *}$ & $0.993(8)$ & $0.250(2)^{* * *}$ \\
\hline \multirow{3}{*}{$\begin{array}{l}\text { Anlamlı } \\
\text { lık } \\
\text { Düzeyi }\end{array}$} & $\% 1$ & -3.506 & -3.506 & -3.503 & -3.503 & 0.739 & 0.739 \\
\hline & $\% 5$ & -2.894 & -2.894 & -2.893 & -2.893 & 0.463 & 0.463 \\
\hline & $\% 10$ & -2.584 & -2.584 & -2.583 & -2.583 & 0.347 & 0.347 \\
\hline
\end{tabular}

Not: $* * *, * * *$ sırasıyla $\% 1, \% 5, \% 10$ düzeyinde anlamlılı̆̆ 1 ifade etmektedir. ADF testinde parantez içindeki değerler Akaike Bilgi kriteri kullanılarak seçilen gecikme uzunlukları olup ve maksimum gecikme uzunluğu 12 olarak alınmıştır. PP testinde optimal gecikme uzunluğu, Bartlett kernel (default) spectral estimation yöntemi ve Newey-West Bandwidth (automatic selection) kriterlerinden yararlanılmıştır.

Tablo 1' de yer alan ADF ve PP testine göre lnDTH, dışında tüm serilerin birim köke sahip olduğu I(1) sonucuna ulaşılmaktadır. ADF ve PP testlerininin tutarlılığını sınayan KPSS(1992) birim kök testi sonucuna göre lnDTH bağımsız değişkeni dışındaki değişkenler I(1) düzeyinde yani birim köklüdür. Dolayısıyla ADF ve PP testlerinin sonucu KPSS testi ile desteklenmektedir. Bu aşamada fark alma işlemi yapılması gerekmektedir. Fark alma işlemi sonucu ele alınan tüm değişkenler durağan $\mathrm{I}(0)$ hale gelmiştir.

İktisadi zaman serilerinin önemli bir özelliği finansal krizler, yapısal değişimler ve uygulanan ekonomi politikalarının etkisi ile birlikte bünyesinde farklı yapısal kırılmalar içermesidir. Bu yapısal kırılmaların etkisini dikkate almayan analizler ise sapmalı katsayı tahminlerine neden olabilmektedir. Burada yapısal kırılmaların etkisini de dikkate alan ZA birim kök testi kullanılmıştır.

\footnotetext{
${ }^{2} \mathrm{Bu}$ çalışmada değişkenlerin doğrusal olduğunu varsayan birim kök testleri kullanılmaktadır. Çalışmada kullanılan değişkenlerin doğrusal olup olmadığının belirlenmesi amacıyla BDS doğrusalsızlık testinden yararlanılmıştır. Yapılan BDS test sonucuna göre değişkenlerin doğrusal bir karekteristik özelliğine sahip oldukları görülmüştür. Bu nedenle birim kök testinin yanısra eştümleşme ve yapısal denklemin tahmini aşamasında doğrusal modelleme tekniklerinden yararlanılmıştır.

${ }^{3}$ Çalışmada kullanılan değișkenler doğal logaritmaları alınarak analize dahil edilmiștir. Logaritmik formun seçiminde MWD testinden yararlanılmıștır. MWD testinde model hem doğrusal hem de logaritmik formda tahmin edilerek doğrusal ve logaritmik modelin tercihine yönelik hipotez testleri oluşturulmaktadır. Elde edilen MWD testi sonuçlarına göre logaritmik form uygun fonksiyonel kalıp olarak seçilmiştir. Ayrıca değişen varyans sorununa karşı etkili olması ve katsayıların kolay yorumlanabilmesi nedeniyle bu çalışmada literatürle uyumlu olarak logaritmik form kullanılmıştır
} 
Tablo 2. Zivot-Andrews Birim Kök Testi

\begin{tabular}{|c|c|c|c|c|}
\hline \multirow{3}{*}{\begin{tabular}{|l} 
DEĞİŞKENLER \\
$\operatorname{lnGDP}$
\end{tabular}} & \multicolumn{4}{|c|}{ Zivot-Andrews Testi } \\
\hline & \multicolumn{2}{|c|}{ Model (A) } & \multicolumn{2}{|c|}{ Model (C) } \\
\hline & $-4,084(1)$ & $2003 \mathrm{Q} 4$ & $-3,967(1)$ & $\overline{2002 Q 3}$ \\
\hline $\operatorname{lnDTH}$ & $-6,521 * * *(2)$ & 2001Q1 & $-6,499 * * *(2)$ & 2001Q1 \\
\hline $\ln R E R$ & $-2,977(4)$ & 2003Q2 & $-2,830(4)$ & 2005Q1 \\
\hline $\operatorname{lnOP}$ & $-2,534(0)$ & 1994Q3 & $-4,389(0)$ & 1995Q1 \\
\hline \multicolumn{5}{|c|}{ Kritik Değerler } \\
\hline & $\% 1$ & \multicolumn{2}{|c|}{$\overline{~ \% 5}$} & $\overline{\% 10}$ \\
\hline Model (A) & $-5,34$ & \multicolumn{2}{|c|}{$-4,93$} & $-4,58$ \\
\hline Model (C) & $-5,57$ & \multicolumn{2}{|c|}{$-5,08$} & $-4,82$ \\
\hline
\end{tabular}

Not: Model A: Ortalama kırılma; Model C: Rejimde (ortalama+eğim) kırılmayı ifade etmektedir. Parantez içindeki değerler gecikme uzunluklarını göstermektedir. ***, $* * * *$ sırasıly $\% 1, \% 5, \% 10$ düzeyinde anlamlılığ ifade etmektedir.

Tablo 2'de yer alan ZA (1992) test sonuçları şu şekilde yorumlanabilir. Model (A) sonuçlarına göre lnDTH için yapısal kırılmalar altında seri durağandır sonucu bulunurken, lnGDP, lnRER ve lnOP için seri birim köklü çıkmıştır. Kırılma tarihleri lnGDP için 2003Q4,lnDTH için 2001Q1, lnRER için 2003Q2, lnOP için 1994Q3 olup söz konusu dönemler ortalamalarda meydana gelen kırılma tarihlerine karşılık gelmektedir. Model A'ya göre lnDTH için test istatistiğinin \%5 önem düzeyinde kritik değerden küçük olduğu görülmektedir. Dolayısıyla değişken yapısal kırılmayla birlikte durağandır. Diğer değişkenlere ait test istatistikleri kritik değerlerden büyüktür. Bu sonuç yapısal kırılmalarla birlikte modelde yer alan diğer değişkenlerin birim kök içerdiği sonucunu ortaya koymaktadır. Model C sonuçlarına göre kırılma tarihleri lnGDP için 2002Q3, lnDTH için 2001Q1, lnRER için 2005Q1 ve lnOP için 1995Q1 olarak belirlenmiştir. $\mathrm{Bu}$ tarihler serilerin hem sabit hem de eğim katsayılarındaki kırılmalar dikkate alınarak hesaplanmaktadır. Ancak seriler analiz edildiğinde dış ticaret hadleri serisi dışında diğer serilerin birim kök içerdiğini belirten temel hipotez kabul edilmektedir.

İktisadi zaman serilerinde ele alınan veri dönemi arttıkça kırılmaların etkisi daha fazla ortaya çıkmaktadır. Özellikle Türkiye ekonomisi için analiz edildiğinde bu durum net bir şekilde görülebilmektedir. Dolayısıyla krizlerinde etkisi ile birlikte değişkenler birden fazla yapısal kırılmayı bünyesinde taşımaktadır. Burada elde edilen sonuçların tutarlılığını desteklemek amacıyla tek kırılmalı birim kök testinin yanısıra iki kırılmalı Lumsdaine ve Papell (1997) birim kök testinden yararlanılmıştır.

Tablo 3. Çift Kırılmalı Lumsdaine- Papell Birim Kök Testi

\begin{tabular}{|c|c|c|c|c|c|c|}
\hline \multirow{3}{*}{$\begin{array}{l}\text { DEĞİŞKENLER } \\
\operatorname{lnGDP}\end{array}$} & \multicolumn{6}{|c|}{ Lumsdaine Papell Testi } \\
\hline & \multicolumn{3}{|c|}{ Model AA } & \multicolumn{3}{|c|}{ Model CC } \\
\hline & $-4,839(1)$ & $2002 \mathrm{Q} 2$ & $2005 \mathrm{Q} 4$ & $-6,795(1)^{*}$ & 2000Q1 & $2007 \mathrm{Q} 4$ \\
\hline $\operatorname{lnDTH}$ & $-6,740 * *(2)$ & 1995Q4 & 2000Q4 & $-6,859(2)^{* *}$ & 1995Q4 & 2000Q4 \\
\hline $\ln R E R$ & $-6,308 * *(1)$ & 1993Q4 & 2010Q4 & $-6,647(1)^{*}$ & 1993Q4 & 2007Q1 \\
\hline $\operatorname{lnOP}$ & $-3,04(0)$ & 1994Q2 & $2007 \mathrm{Q} 2$ & $-6,137(0)$ & 1997Q3 & 2007Q2 \\
\hline \multicolumn{7}{|c|}{ Kritik Değerler } \\
\hline & $\% 1$ & \multicolumn{2}{|c|}{$\% 5$} & \multicolumn{3}{|c|}{$\% 10$} \\
\hline Model AA & $-6,94$ & \multicolumn{2}{|c|}{$-6,24$} & \multicolumn{3}{|c|}{$-5,96$} \\
\hline Model CC & $-7,34$ & \multicolumn{2}{|c|}{$-6,82$} & \multicolumn{3}{|c|}{$-6,49$} \\
\hline
\end{tabular}

Not: Model AA: Ortalama kırılma; Model CC: Rejimde (ortalama+eğim) kırılmayı ifade etmektedir. Parantez içindeki değerler gecikme uzunluklarını göstermektedir. ***, **** sırasıyla \% $1, \% 5, \% 10$ düzeyinde anlamlılığı ifade etmektedir.

Gsyh, reel kur, dışa açıklık ve dış ticaret hadleri değişkenleri bu bilgiler 1şı̆̆ında 1990-2015 verileri ile uygulanmıştır. Yapılan çift kırılmalı Lumsdaine - Papell birim kök testi sonucu dış ticaret hadleri dışındaki tüm 
değişkenler birim köklüdür. Model AA'da, lnGDP 2002Q2 ve 2005Q4 yıllarında, lnDTH için 1995Q4 ve 2000Q4, lnRER için 1993Q4 ve 2010Q4, lnOP için 1994Q2 ve 2007Q2 tarihlerinde kırılmalar gözlenmektedir. Model CC için ise lnGDP 2000Q1 2007Q4, lnDTH 1995Q4 ve 2000Q4, lnRER için 1993Q4 ve 2007Q1, lnOP için 1997Q3 ve 2007Q2 yıllarında kırılmalar gözlenmiştir.

Diğer bir yapısal kırılma testi ise Lee-Strazicich (2003) tarafından önerilmektedir. LM istatistiğine dayanan bu test iki yapısal kırılmayla beraber değişkenlerin birim kök yapılarını test edebilmektedir. Testin önemli bir özelliği de küçük örneklemlerde etkin sonuç verebilmesidir. Lumsdaine - Papell birim kök testine alternatif olarak geliştirilen test, sonuçların tutarlılığını desteklemesi açısından bulgularımızın güvenilirliğini artırmaktadır.

Tablo 4. Çift Kırılmalı Lee-Strazicich Birim Kök Testi

\begin{tabular}{|c|c|c|c|c|c|c|}
\hline \multirow{3}{*}{$\begin{array}{l}\text { DEĞİŞKENLER } \\
\operatorname{lnGDP}\end{array}$} & \multicolumn{6}{|c|}{ Lee-Strazicich Testi } \\
\hline & \multicolumn{3}{|c|}{ Model AA } & \multicolumn{3}{|c|}{ Model CC } \\
\hline & $-2.139(1)$ & $2002 \mathrm{Q} 3$ & $2006 \mathrm{Q} 4$ & $-5,193(1)$ & 2002Q1 & 2006Q1 \\
\hline $\ln D T H$ & $-5,506(2) * * *$ & 1995Q4 & 2009Q1 & $\begin{array}{c}-6,452 * * * \\
(3)\end{array}$ & 1995Q4 & $2003 \mathrm{Q} 2$ \\
\hline $\ln R E R$ & $-3,519(1)^{*}$ & 2001Q4 & 2008Q2 & $-5,686 *(2)$ & 1993Q4 & 2007Q4 \\
\hline $\ln O P$ & $-2,755(0)$ & 1995Q1 & $2007 \mathrm{Q} 4$ & $-3,921(2)$ & 1994Q2 & 2008Q1 \\
\hline \multicolumn{7}{|c|}{ Kritik Değerler } \\
\hline & \multicolumn{3}{|c|}{$\% 5$} & \multicolumn{3}{|c|}{$\overline{\% 10}$} \\
\hline Model AA & \multicolumn{3}{|c|}{$-3,84$} & \multicolumn{3}{|c|}{$-3,50$} \\
\hline & \multicolumn{6}{|c|}{ Kırılma Noktaları } \\
\hline Model CC & \multicolumn{6}{|c|}{$\lambda_{2}$} \\
\hline$\lambda_{1}$ & \multicolumn{2}{|l|}{0.4} & \multicolumn{2}{|c|}{0.6} & \multicolumn{2}{|r|}{0.8} \\
\hline 0.2 & \multicolumn{2}{|c|}{$\begin{array}{lll}-6.16 & -5.59 & -5.27 \\
\end{array}$} & \multicolumn{2}{|c|}{$\begin{array}{lll}-6.41 & -5.74 & -5.32\end{array}$} & -6.33 & $\begin{array}{ll}-5.71 & -5.33\end{array}$ \\
\hline 0.4 & \multicolumn{2}{|c|}{$-6.45-5.67$} & \multicolumn{2}{|c|}{$\begin{array}{lll}-5.31 & -6.42 & -5.65\end{array}$} & \multicolumn{2}{|c|}{-5.32} \\
\hline 0.6 & \multicolumn{2}{|l|}{-6.32} & \multicolumn{2}{|c|}{$-5.73 \quad-5.32$} & & \\
\hline
\end{tabular}

Not: Model AA: Ortalama kırılma; Model C: Rejimde (ortalama+eğim) kırılmayı ifade etmektedir. Parantez içindeki değerler gecikme uzunluklarını göstermektedir. ***, ${ }^{* * *}$, sırasıyla \% $1, \% 5, \% 10$ düzeyinde anlamlılığı ifade etmektedir.

Uygulanan çift kırılmalı Lee-Strazicich testi Model AA için, lnGDP bağımlı değişkeni 2002Q3 ve 2006Q4, lnDTH bağımsız değişkeni 1995Q4 ve 2009Q1, lnRER için 2001Q4 ve 2008Q2, lnOP için 1995Q1 ve 2007Q4 yıllarında kırılmalar saptanmıştır.

Tablo 5. Birim Kök Testlerin Sonuçları

\begin{tabular}{|l|c|c|}
\hline & LNDTH & LNGDP, LNRER, LNOP, \\
\hline ADF Testi & Birim kök yoktur. & Birim kök vardır \\
\hline Philips Perron Testi & Birim kök yoktur & Birim kök vardır. \\
\hline KPSS Testi & Birim kök vardır & Birim kök yoktur. \\
\hline $\begin{array}{l}\text { Zivot- Andrews Testi } \\
\text { (Model A- C için) }\end{array}$ & $\begin{array}{c}\text { Yapısal kırılmalar altında trend } \\
\text { durağandır. }\end{array}$ & Birim kök vardır. \\
\hline $\begin{array}{l}\text { Lumsdaine Papel Testi } \\
\text { (Model AA- CC için) }\end{array}$ & $\begin{array}{c}\text { Yapısal kırılmalar altında trend } \\
\text { durağandır. }\end{array}$ \\
\hline $\begin{array}{l}\text { Lee- Strazicich Testi } \\
\text { (Model AA- CC için) }\end{array}$ & $\begin{array}{c}\text { Birim kök yoktur. } \\
\end{array}$ & $\begin{array}{c}\text { Yapısal kırılmalar altında seri birim } \\
\text { kök içerir. }\end{array}$ \\
\hline
\end{tabular}

Kaynak: Yazar tarafindan hazırlanmıştır.

Tablo 5'de belirtildiği üzere değişkenler için birim köklü ya da durağan olduğu sonucuna ulaşılamamaktadır. Literatürde sıklıkla kullanılan Engle-Granger (1987), Johansen (1988) gibi eştümleşme testleri değişkenlerin aynı dereceden bütünleşik olmasını gerektirmektedir. Ancak, Peseran vd. (1999) tarafından önerilen ve farklı dereceden 
bütünleşik değişkenler arasındaki ilişkinin ortaya konmasına olanak sağlayan ARDL modeli aracılığıyla değişkenler test edilebilmektedir.

ARDL Testi’nin uygulanması için öncelikle Pesaran'ın sınır testi kullanılmaktadır. Bu testi kullanırken alt ve üst değerlere göre eş bütünleşme olup olmadığı test edilir. F istatistiği alt ve üst değerlerle karşılaştırılır. F istatistiği üst değerden büyükse Ho hipotezi olan eştümleşme yoktur ifadesi reddedilir. Diğer bir ifadeyle eştümleşmenin varlığ kabul edilir. F istatistiği alt ve üst değerlerle karşılaştırılır. F istatistiği üst değerden büyükse Ho hipotezi olan eştümleşme yoktur ifadesi reddedilir. Diğer bir ifadeyle eştümleşmenin varlığı kabul edilir. F istatistiği, alt sınırdan küçük ise, eş bütünleşme yoktur yani Ho eştümleşme yoktur ifadesi kabul edilir.

Tablo 6. Sınır Test İstatistiği Sonuçları

\begin{tabular}{|c|c|c|}
\hline $\mathrm{k}$ & F istatistiği & Kritik Değer \\
\hline 3 & 6,779 & $\begin{array}{c}\text { Alt Sinır I(0) } \\
4,01\end{array}$ \\
\hline
\end{tabular}

Not:*k, bağımsız değişken sayısıdır. Kritik değerler Pesaran vd. (2001:300)’ deki Tablo CI(iii)’ten alınmıştır. Kritik değerler \% $\%$ önem düzeyindeki kritik değerlerdir.

Sonuçlara göre F istatistiği (6.799), üst değerden (5.07 ) büyüktür. Dolayısıyla Ho hipotezi reddedilir. Eştümleşme vardır sonucuna ulaşılır.

Tablo 7'de diş ticaret hadlerinin ekonomik büyüme üzerindeki etkisini gösteren ARDL $(2,3,0,4)$ modeli tahmin sonuçları yer almaktadır. ARDL modelinin gecikme uzunluğunun belirlenmesinde Akaike bilgi kriterinden (AIC) yararlanılmıştır. Modelde çeyreklik frekansa sahip verilerle çalışıldığ 1 için maksimum gecikme uzunluğu 4 olarak belirlenmiştir. Otokorelasyon sorununu ortadan kaldıran gecikme uzunluğu optimal gecikme uzunluğu olarak belirlenmiştir. ARDL modeli katsayıları doğrudan yorumlanmayıp buradan elde edilen uzun ve kısa dönem katsayılar yorumlanmaktadır. ARDL modeline ait $\mathrm{F}$ istatistiği ve $R^{2}$ değerlerine bakıldığında modelin anlamlı ve açıklama gücünün yüksek olduğu söylenebilir.

Modelde bağımlı değişken LNGDP'dir. Parantez içerisindeki ifadeler $(2,3.0,4)$ bağımlı ifade en başta olmak üzere, bağımlı ve bağımsız değişkenlerin gecikme uzunluğunu vermektedir. Örneğin, bağımlı değişken olan LNGDP'nin gecikme uzunluğu 2 iken, LNDTH'nin gecikme uzunluğu 3, LNOP'ın gecikme uzunluğu 0 ve son olarak LRDK'nın gecikme uzunluğu 4' tür. Bağımlı değişkenin sadece gecikme değeri ele alınırken, bağımsızın kendisiyle birlikte gecikme değeri ele alınır. Buradaki gecikme değerini belirleyen ise Akaike değeridir. Gecikme değerleri kullanılarak model tahmini yapilır.

ARDL modelinden hareketle uzun ve kısa dönem tahminler elde edilir. Kısa ve uzun dönemden elde edilen katsayı tahminleri yorumlanır. Kısa dönem modelin istikrar testleri (Otokorelasyon, değişen varyans, Cusum testi, Model Spesifikasyon testi, Ramsey - Reset testleri) uygulanır. Bu bilgiler ışı̆̆ında ARDL kısa ve uzun dönem katsayıları tablo 7 ve 8 'de aşağıda verilmiştir.

Tablo 7. ARDL $(2,3,0,4)$ Modeli Sonuçları ve Hesaplanan Uzun Dönem Katsayıları

\begin{tabular}{||l|c|c|c||}
\hline \multicolumn{3}{|c|}{ Bağımlı Değişken: LGDP } \\
\hline \hline Bağımsız Değişkenler & Katsayılar & Standart Hata & t istatistiği \\
\hline \hline LGDP(-1) & 0.839922 & $\mathbf{0 . 1 2 7 6 5 8}$ & $\mathbf{6 . 5 7 9 4 8 1 * * *}$ \\
\hline LGDP(-2) & $-\mathbf{0 . 3 7 8 6 5 7}$ & $\mathbf{0 . 1 2 4 9 8 9}$ & $\mathbf{- 3 . 0 2 9 5 1 9 * *}$ \\
\hline LDTH & $-\mathbf{0 . 1 0 0 6 6 1}$ & $\mathbf{0 . 1 3 6 1 4 2}$ & $\mathbf{- 0 . 7 3 9 3 8 1}$ \\
\hline LDTH(-1) & 0.340563 & $\mathbf{0 . 1 5 0 4 3 1}$ & $\mathbf{2 . 2 6 3 9 0 8 * *}$ \\
\hline LDTH(-2) & $-\mathbf{0 . 2 7 3 4 0 2}$ & $\mathbf{0 . 1 5 2 4 3 6}$ & $\mathbf{- 1 . 7 9 3 5 5 3 *}$ \\
\hline LDTH(-3) & 0.200140 & $\mathbf{0 . 1 1 5 9 2 0}$ & $\mathbf{1 . 7 2 6 5 3 1 *}$ \\
\hline LOP & 1.478777 & 0.269944 & $\mathbf{5 . 4 7 8 0 9 2 * * *}$ \\
\hline LRDK & 0.295864 & $\mathbf{0 . 1 4 5 3 3 6}$ & $\mathbf{2 . 0 3 5 7 1 6 * *}$ \\
\hline
\end{tabular}




\begin{tabular}{||l|c|c|c||}
\hline LRDK(-1) & -0.077048 & 0.169636 & -0.454195 \\
\hline LRDK(-2) & 0.546056 & 0.165174 & $3.305939 * * *$ \\
\hline LRDK(-3) & -0.295414 & 0.166402 & $-1.775301 *$ \\
\hline LRDK(-4) & 0.416673 & 0.123286 & $3.379721 * * *$ \\
\hline TREND & 0.003698 & 0.001142 & $3.494575 * * *$ \\
\hline C & -4.088482 & 1.169951 & $3.238898 * * *$ \\
\hline
\end{tabular}

\begin{tabular}{|c|c|c|c|}
\hline \multicolumn{4}{|c|}{ Hesaplanan Uzun Dönem Katsayıları } \\
\hline Sabit & -10.863294 & 2.230532 & $-4.870270 * * *$ \\
\hline LDTH & 0.667512 & 0.234571 & $2.845670 * * *$ \\
\hline LOP & 3.353264 & 0.405916 & $8.260987 * * *$ \\
\hline LRDK & 1.526993 & 0.271653 & $5.621107 * * *$ \\
\hline TREND & 0.005885 & 0.001894 & $3.106362 * * *$ \\
\hline D2003Q4 & 16.037 & 7.223 & $2.220 * *$ \\
\hline D2007Q3 & -11.878 & 5.998 & $-1.980 *$ \\
\hline $\mathbf{R}^{2}=0.990$ & Düzeltilmiş $\boldsymbol{R}^{\mathbf{2}}=0.987$ & & 0.33 \\
\hline
\end{tabular}

Not:*,**,*** sırasıyla \%10, \%5 ve \%1 önem düzeylerini göstermektedir. Kırılma tarihleri Bai-Perron çoklu yapısal kırılma testi yardımıyla belirlenmiştir. Kırılma sayısı iki olarak tespit edilmiş ve ARDL modeline dahil edilmiştir. Böylece ARDL modeli yapısal kırılmaları dikkate alacak şekilde genişletilmiştir.

ARDL modelinden elde edilen uzun dönem katsayılar incelendiğinde şu sonuçlara ulaş1labilir. D1ş ticaret hadlerinin katsayısı pozitif ve istatistiksel olarak anlamlıdır. Dış ticaret hadlerinde (LDTH) meydana gelen \% 1 oranındaki artış uzun dönemde gayri safi yurtiçi hasıla üzerinde \% 0.667 oranında artışa yol açmaktadır. Dışa açıklık katsayısı pozitif olup istatistiki olarak anlamlıdır. Dışa açıklık oranında meydana gelen \%1'lik artış uzun dönem gayrisafi yurtiçi hasıla üzerinde \%3.353'lük artışa neden olmaktadır. Yine reel döviz kuru katsayısının işareti pozitif ve anlamlı olup reel döviz kurunda meydana gelen \%1'lik bir artış gayrisafi yurtiçi hasıla üzerinde \%1.526'lık bir artış meydana getirmektedir. Uzun dönem trend katsayısının işareti pozitif bulunmuştur. Bu sonuç ele alınan her bir çeyrek dönem boyunca gayri safi yurtiçi hasılanın ortalama olarak \% $0.5\left(0.005^{*} 100\right)$ oranında artması anlamına gelmektedir. Bu çalışmada literatürde yer alan diğer ARDL modellerinden farklı bir yaklaşım sergileyerek kırılmaların etkisi de modele dahil edilmiştir. Böylece kırılmalar altında uyarlanmış ARDL modeli tahmin edilen katsayıların güvenilirliğini de artırmaktadır. Kırılma tarihlerinin belirlenmesinde Bai-Perron çoklu yapısal kırılma testinden yararlanılmıştır. Birinci kırılma tarihi 2003Q4, ikinci kırılma tarihi ise 2007Q3 olarak tespit edilmiştir. Birinci kırılma döneminin katsayısının işareti pozitif iken, ikinci kırılma döneminin katsayısı negatiftir. Birinci kırılma dönemi ekonominin genişleme dönemi olarak kabul edilirken, ikinci yapısal kırılma dönemi 2008 küresel krizinin etkisi ile beraber daralma dönemi olarak nitelendirilebilir.

Uzun dönemde değişkenler arasında görülen eşbütünleşme ilişki kısa dönemli bir hata düzeltmenin varlığını göstermektedir. Hata düzeltme terimi olarak adlandırılan bu katsayının işareti ve yorumlanması önemlidir. Negatif işaretli ve istatistiksel olarak anlamlı bulunan hata düzeltme katsayısı (ECM (-1)) değişkenler arasında görülen kısa dönemli sapmaların ortadan kalkarak değişkenlerin uzun dönemde dengeye geldiği şeklinde yorumlanabilir. Sapmaların ortadan kalkarak uzun dönem dengeye gelme hızı ise $\frac{1}{\operatorname{ECM}(-1)}$ formülü ile hesaplanmaktadır. 
Tablo 8. Kısa Dönem Tahmin Sonuçları

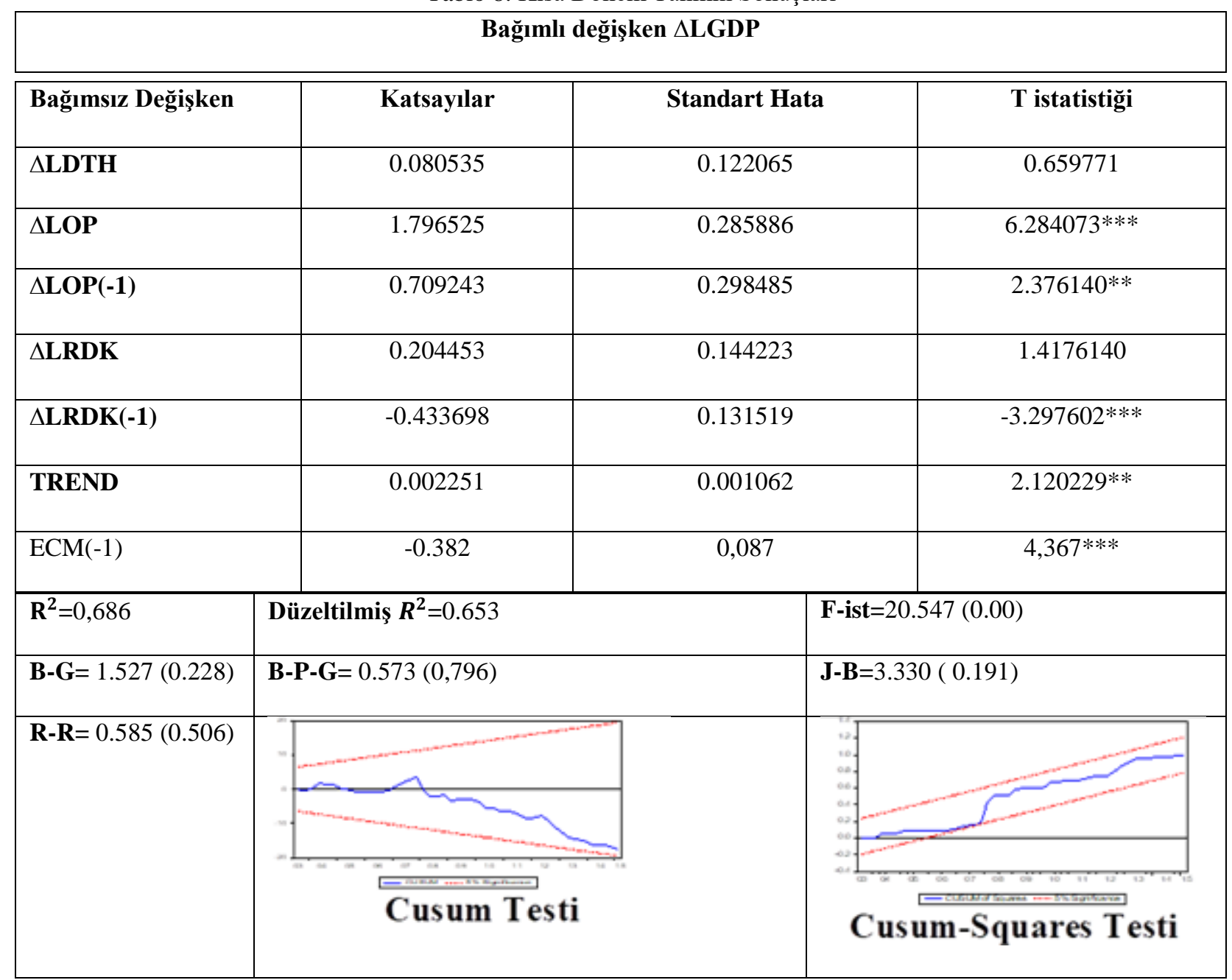

\section{Sonuç ve Öneriler}

Çalışmada elde edilen bulgular bir bütün olarak değerlendirildiğinde şu sonuçlara ulaşılmıştır: uzun dönemde dış ticaret hadlerinin ekonomik büyüme üzerindeki etkisi pozitif ve anlamlıdır. Dış ticaret hadlerindeki \%1 lik bir artış, uzun dönemde ekonomik büyüme üzerinde $\% 0,667$ lik bir artışa neden olmaktadır. Reel döviz kurundaki $\% 1$ lik bir artış uzun dönem ekonomik büyüme üzerinde $\% 1,526^{\circ}$ l1k pozitif bir etkiye neden olurken, dışa açıklık (OP) değişkeninin uzun dönem katsayı tahmin sonucuna bakıldığında ekonomik büyüme üzerinde pozitif ve anlamlı bir etkisinin olduğu görülmektedir. Bu bağlamda dışa açıklıktaki \%1' lik bir artış ekonomik büyüme üzerinde \% 3,35 ' lik bir artışa yol açmaktadır.

Çalışma, dış ticaret hadlerindeki pozitif yönlü bir gelişmenin ekonomik büyümeyi olumlu yönde etkileyeceğini doğrular niteliktedir. Bu bağlamda literatürle uyumludur. İthal girdi bağımlısı ticaret yapısı yerine, ithal edilen girdilerin üretilerek katma değerinin ülke içerisinde kalması, söz konusu ülkenin ekonomik büyümesinin artmasını sağlayacaktır. Buna ek olarak, ihraç ürünlerinin katma değeri ne kadar yüksek olursa ekonomik büyüme üzerinde o kadar etkili olacaktır. Bu nedenle ülke ekonomisi açısından büyük önem arz eden yüksek katma değerli ürünlere olan dış bağımlılığımız Ar-Ge yoğun, teknoloji yoğun mallar üretilerek azaltılmalıdır. Sonuç olarak söylenebilir ki, Türkiye' de uygulanacak bu politikalar uzun dönemde dış ticaret hadlerinde pozitif etki yaratarak, ekonomik büyüme üzerinde anlamlı bir etki yaratacaktır. 


\section{KAYNAKÇA}

Bal H., Çiftçi H., İşcan E., \& Serin D., 2016."İhracata Dayalı Büyüme: Teknolojik Bakış, Internatıonal Conference On Eurasian Economies." ,s.312

Blattman C., Hwang J., Williamson J.G., 2003."The Terms of Trade and Economic Growth in the Periphery 1870-1938." NBER Working Paper No. 9940.

Cashin P., Mcdermott J., 1998. "Terms of Trade Shocks and Current Account, International Monetary Fund, Working Paper." s. 177.

Çakır, M., 2009.Terms of Trade and Economic Growth of Emerging Market Economies, International Conference on Administration and Business

Ekinci R., Tüzün O., Kahyaoğlu H., 2015."Dış Ticaret Hadleri Ekonomik Büyüme İlişkisi: Türkiye Üzerine Bir Uygulama." Optimum Ekonomi ve Yönetim Bilimleri Dergisi, , Cilt: 2, Sayı: 2, ss.83-100.

Enrique Mendoza, "Terms of Trade Uncertainty and Economic Growth” Journal of Development Economics, Vol.54, 1997, 323-356.

Gerni C., Emsen S., \& Değer K, 2008,"İthalata Dayalı İhracat ve Ekonomik Büyüme: 1980-2006 Türkiye Deneyimi.", 2.Ulusal İktisat Kongresi, İzmir, s.5.

Hadass Y., Williamson J.G.,2001, "Terms of Trade Shocks and Economic Performance 1870-1940: Prebisch and Singer Revisited.", NBER Working Paper No. 8188.

Jawaid, T., Waheed A., 2011."Effects of Terms of Trade and its Volatility on Economic Growth: A Cross Country Empirical Investigaton, Transition Studies Review 18(2):217-229.

Kwiatkowski D., Phillips P., Schmidt P., Shin Y., 1992. "Testing the null hypothesis of stationary against the alternative of a unit root: How sure are we that economic time series have a unit root?", Journal Economics, Cilt: 54, , s. 159178, North- Holland.

Lumsdaine R., Papell D. H., 1997 ."Multiple trend breaks and the unit root hypothesis", Review of Economics and Statistics, , Cilt: 79, Say1: 2, pp. 212-18.

Misztal P., 2010."The Harberger-LaursenMetzler Effect Theory and Practice in Poland, The Romanian Economic Journal." Year XIII, no. 38.

Pesaran M.H., Shin Y., 1999."An Autoregressive Distributed Lag Modelling Approach to Coentegration Analysis." Sfreddo C., 2004."International Price and Terms of Trade Effects on Factor Productivity: International Comparisons." Zivot, E. and D. Andrews,1992."Further evidence of great crash, the oil price shock and unit root hypothesis", Journal of Business and Economic Statistics, 10, 251-270. 